\title{
Management of Multidrug Resistant Infections in Lung Transplant Recipients with Cystic Fibrosis
}

\author{
Jaideep Vazirani ${ }^{\prime}$ \\ Thomas Crowhurst (iD ${ }^{1,2}$ \\ C Orla Morrissey ${ }^{3}$ \\ Gregory I Snell' \\ 'Lung Transplant Service, Department of \\ Respiratory Medicine, The Alfred \\ Hospital and Monash University, \\ Melbourne, VIC, Australia; ${ }^{2}$ Department \\ of Medicine, The University of Adelaide, \\ Adelaide, SA, Australia; ${ }^{3}$ Department of \\ Infectious Diseases, The Alfred Hospital \\ and Monash University, Melbourne, Vic, \\ Australia
}

\begin{abstract}
Cystic fibrosis (CF) is an inherited multisystem disease characterised by bronchiectasis and chronic respiratory infections which eventually cause end stage lung disease. Lung transplantation (LTx) is a well-established treatment option for patients with CFassociated lung disease, improving survival and quality of life. Navigating recurrent infections in the setting of LTx is often difficult, where immune suppression must be balanced against the constant threat of infection. Sepsis/infections are one of the major contributors to post-LTx mortality and multiresistant organisms (eg, Burkholderia cepacia complex, Mycobacterium abscessus complex, Scedosporium spp. and Lomentospora spp.) pose a significant threat to survival. This review will summarize current and novel therapies to assist with the management of multiresistant bacterial, mycobacterial, viral and fungal infections which threaten the CF LTx cohort.
\end{abstract}

Keywords: lung transplant, cystic fibrosis, multidrug resistant infection

\section{Introduction}

Cystic fibrosis (CF) is the most common lethal autosomal recessive disorder of the Caucasian population, causing multisystem failure through defects in a single protein (CF transmembrane conductance regulator, CFTR). ${ }^{1}$ CFTR is highly expressed in respiratory epithelial cells, and its impaired function leads to airway dehydration, progressive inflammation and reduced mucociliary clearance. A diverse and pathogenic microbiome, repeated pulmonary infection and a large cumulative exposure to antimicrobial agents are the hallmarks of $\mathrm{CF}^{2}$ Median life expectancy for CF patients in the contemporary age of multidisciplinary management and CFTR directed therapy is 32-46 years. ${ }^{3,4}$

Lung transplantation (LTx) is a well-established treatment option for patients with $\mathrm{CF}$-associated end-stage lung disease, improving survival and quality of life. ${ }^{5}$ Globally, from 1995-2016, 8484 CF patients underwent LTx. CF is the third most common indication for adult LTx, and the most common reason for pediatric LTx. ${ }^{6}$ Survival following LTx is highest for CF compared to other indications (chronic obstructive pulmonary disease, interstitial lung disease, etc), with the latest international registry data demonstrating a median five-year survival of $>50 \%$. The leading cause of death amongst adults with CF who have had a LTx is pulmonary infection. $^{7}$

Improved management and survival amongst pre-LTx CF patients have been reflected in the gradually increasing median age of the CF LTx recipient. ${ }^{7}$ Although post-LTx survival is thought to improve when recipients are past adolescence at
Correspondence: Jaideep Vazirani Tel +6I 390762000

Email jaideepvazirani55@gmail.com 
time of LTx, ${ }^{8}$ an older cohort brings new challenges. Over time, the evolving microbiome within the CF lung acquires increasing resistance, reflecting cumulative exposure to antimicrobial agents. ${ }^{9}$ There is increasing concern regarding the re-emergence of multiresistant infections following LTx, with a limited antimicrobial armamentarium at hand.

Over the past decade, advances in culture-independent sequence-based analysis of microbial genomes has highlighted the richness and complexity of the CF microbiome, beyond the pathogens classically linked to CF (eg, Staphylococcus aureus, Pseudomonas aeruginosa, Burkholderia cepacia) ${ }^{10}$ Although LTx replaces both native and heavily infected CF-lungs, many microbiome studies demonstrate preservation of the pre-LTx lower airway microbiome post-LTx. ${ }^{11}$ This review will summarize the emerging multiresistant bacterial, mycobacterial, viral and fungal infections which threaten the CF LTx cohort, together with some novel therapies to assist with management of these infections.

\section{Bacterial Infections Gram-negative Bacteria}

Gram-negative bacteria represent the vast majority of pathogens featured in a recent World Health Organization (WHO) list of "priority pathogens" which pose the greatest threat to humans. ${ }^{12}$ Major adversaries featuring on this list, include Stenotrophomonas maltophilia, Acinetobacter baumannii and Enterobacteriaceae, and are commonly found within the CF microbiome. ${ }^{13,14}$ Traditionally, postLTx bacterial infections caused by known pre-LTx colonizers within the host have been considered manageable. ${ }^{15}$ Particularly, the presence of pre-LTx multiresistant $P$. aeruginosa which has been linked to increased frequency of post-LTx pneumonia, but importantly is not linked to a decreased survival. ${ }^{16,17}$ Microbiome studies, specifically examining resistance patterns of gram-negative bacteria amongst CF-LTx patients are scarce; however, treating post-LTx re-emergent gram negatives in the current climate of growing antibacterial resistance is increasingly problematic.

Amongst gram-negative pathogens, resistance to $\beta$-lactam antibiotics is largely mediated by $\beta$-lactamases. Carbapenems will overcome $\beta$-lactamases; however, are themselves neutralized by metallo- $\beta$-lactamases (MBL). ${ }^{18}$ MBL expression by $P$. aeruginosa represents one of the recent and most challenging resistance patterns clinicians have to manage. MBL-producing $P$. aeruginosa has been described in a postoperative CF-LTx patient, who ultimately needed a lung lobectomy eight months following LTx due to atelectasis with suppuration. ${ }^{19}$ Similarly, a further case report of fatal empyema caused by MBLproducing $P$. aeruginosa in a CF-LTx patient was associated with failure of all antimicrobial therapy and required a right pneumonectomy. ${ }^{20}$

Ceftolozane-tazobactam was the first amongst the second-generation $\beta$-lactams with $\beta$-lactamase activity. There is growing experience with using it against extended spectrum $\beta$-lactamase (ESBL) producing Enterobacteriaceae, and it has demonstrated activity against multidrug resistant P. aeruginosa. ${ }^{21}$ The chemical structure of ceftolozane is similar to ceftazidime, with the exception of a modified side chain which potentiates antipseudomonal activity. ${ }^{22}$ Successful use in LTx recipients with ventilator-acquired pneumonia and complicated intra-abdominal infections have been reported. ${ }^{23,24}$ Ceftolozane-tazobactam, however, lacks activity against carbapenemase-producing organisms.

Novel agents with activity against carbapenamase-producing gram-negative bacteria (including carbapenamaseresistant Enterobacteriaceae, CRE) such as ceftazidime/ avibactam and meropenem/vaborbactam, have changed the management of invasive CRE, with increased cure rates, decreased mortality and decreased acute kidney injury when compared to colistin-based therapies. ${ }^{25}$ In addition, the use of aztreonam together with ceftazidime/avibactam has been suggested as a strategy against ESBL with MBL expression, to avoid acquired resistance. ${ }^{26}$

Infections with B. cepacia complex (BCC) in the CFlower airway have been associated with significantly increased early post-LTx mortality relating to overwhelming chest sepsis (pneumonia, mediastinitis, and empyema). ${ }^{27}$ Many centers still consider isolation of BCC an absolute contraindication to LTx. Smaller studies attribute the increased mortality seen with BCC to the subspecies $B$. cenocepacia specifically. ${ }^{28}$ Newer metagenomic tools have identified specific strains of $B$. cenocepacia (eg, those with ET12) which appear to have increased pathogenicity. The treatment of BCC is notoriously difficult, and no standard guidelines for management exists. Prolonged multidrug regimens are usually prescribed using local institution expertise and sensitivity testing. A reasonable combination includes inhaled tobramycin, trimethoprim-sulfamethoxazole, minocycline and a $\beta$-lactam (usually meropenem or ceftazidime). ${ }^{29}$ In 
addition, some success with ceftazidime/avibactam and meropenam/varobactam has been reported against $\mathrm{BCC}$ in the CF-LTx cohort.

New strategies for management of gram-negative infections are under development. High-dose adjunct inhaled nitric oxide has recently been reported as safe, well tolerated and of clinical benefit in an adolescent with CF suffering from B. multivorans infection. ${ }^{30} \mathrm{~A}$ Phase II placebo-controlled clinical trial of inhaled nitric oxide amongst CF-LTx patients is currently underway (NCT02498535). Primary outcomes include change in $\mathrm{FEV}_{1}$ and sputum colony forming units after a seven-day course of inhaled nitric oxide. In addition, technology to facilitate phage therapy (ie, the therapeutic application of viruses that infect bacteria) has existed for decades, ${ }^{31}$ and recent reports confirm success of phage/antibiotic synergy against gram-negative pathogens. ${ }^{32}$ Clinical trials for phage therapy in CF are currently underway (NCT04684641). Topical disinfectant application at the time of CF-LTx has also been explored and demonstrates some degree of success. A single center recently reported reduced colonization with multidrug resistant pathogens (particularly $P$. aeruginosa) at one year post-LTx when a $2 \%$ taurolidine bronchial lavage was applied intra-op to recipient native bronchi and pleural cavities. ${ }^{33}$

\section{Nontuberculous Mycobacteria (NTM)}

NTM have an estimated annual prevalence of $12 \%$ amongst patients with CF. Recent United States CF patient registry data demonstrated $20 \%$ had isolated a pathogenic NTM species at least once over a 5-year period. ${ }^{34}$ The literature on NTM infection in solid organ transplant recipients is very limited, apart from case reports and institutional experiences. ${ }^{35} M$. abscessus complex (MABC) is the second most common NTM (following M. avium complex, MAC) and is emerging as one of the most worrisome NTM amongst CF-LTx patients. Infection is often associated with accelerated lung function decline and complicated toxic multidrug therapy which may span years. ${ }^{36}$ MABC most commonly infects the pleuropulmonary space; however, cutaneous sites, operative sites, and disseminated disease have been reported. ${ }^{35}$ A recent case report describes prolonged multidrug therapy for recurrent MABC in a CF-LTx recipient with cutaneous and pulmonary infection complicated by drug toxicities causing multiorgan failure and loss in lung allograft function. ${ }^{37}$

An isolation of NTM does not always confer disease, and recent guidelines highlight the clinical and microbiological features for diagnosis. ${ }^{38}$ Given the absence of randomized clinical trial data, treatment is based on expert opinion. Macrolides are the cornerstone of NTM treatment; however, treatment is limited by resistance. $^{39}$ Therapy is guided by local epidemiology and pathogen sensitivity, and usually involves an induction phase with multiple intravenous and oral agents (including macrolide/clofazimine, amikacin and $\beta$-lactam) and a suppressive phase with multiple oral/inhaled drugs (macrolide, fluoroquinolone, inhaled aminoglycoside \pm clofazimine). In addition, surgical intervention may be required, hyperbaric oxygen therapy can be considered ${ }^{40}$ and reduction in immune suppression should be considered. $^{37,41}$

Several novel therapies for treatment of NTM have recently emerged. Amikacin liposome inhalation suspension (ALIS) is a formulation of the aminoglycoside designed to facilitate targeted drug delivery whilst minimizing systemic exposure. ${ }^{42}$ The molecule is phagocytosed by respiratory macrophages and delivered directly to infected respiratory cells. A recent prospective openlabel randomized study revealed that addition of ALIS to guideline-based therapy for treatment refractory MAC lung disease achieved greater culture conversion by sixmonths. ${ }^{43}$ Recent studies report success of regimens involving combination clofazimine and amikacin inhalational therapy, with significant synergistic activity and ongoing culture negativity in $43 \%$ after 12-months in MABC airway infections. ${ }^{39}$ Linezolid use against pulmonary MABC has been reported; however, treatment limiting side effects such as cytopenia and peripheral neuropathy are potential complications. ${ }^{44}$ Tedizolid has reported greater in vitro activity than linezolid against $\mathrm{MABC}$; however, a large single center study reports no significant safety benefit of tedizolid over linezolid for treatment of NTM amongst solid organ transplant recipients. ${ }^{45}$

\section{Viral Infections Cytomegalovirus}

Cytomegalovirus (CMV) is a $\beta$-herpesvirus which is usually acquired via primary infection in childhood or early adulthood and thereafter establishes latency in monocytes, megakaryocytes, dendritic cells and myeloid progenitor cells. ${ }^{46}$ It is a major cause of morbidity/mortality after LTx when immunosuppression facilitates viral reactivation, manifesting as asymptomatic viremia, viremia with nonspecific symptoms (fever and malaise) or 
evidence of tissue invasion with end-organ damage (most commonly pneumonitis). Fifty percent of CF-LTx recipients are seronegative pre-LTx for CMV. CMV reactivation is associated with increased rates of acute cellular rejection and chronic lung allograft dysfunction. ${ }^{47}$ Before universal prophylaxis with valganciclovir, 54-95\% of lung transplant recipients developed viraemia and over half developed disease. ${ }^{48}$ This has significantly improved with prophylaxis, but CMV remains a serious problem especially for the CF-LTx at highest risk, (ie, donor seropositive/recipient seronegative mismatch LTx). ${ }^{49}$

The development of viral resistance to ganciclovir/valganciclovir is one of the complications of prolonged antiviral exposure, affecting approximately $2 \%$ of lung transplant recipients and nearly $5 \%$ of serological mismatches with three-year mortality rates as high as $70 \%{ }^{50}$ $\mathrm{CF}$ is also associated with an increased risk of CMV resistance. $^{51}$ Resistance testing should be performed when CMV does not respond to ganciclovir therapy (eg, CMV viral load increases on therapy or fails to fall by a $\log$ within seven days of commencement of therapy). Resistance is most often mediated by mutations in UL97, which encodes a viral enzyme necessary for the activation of ganciclovir. Mutations in UL54 usually arise as a second step and additionally confer resistance to foscarnet. ${ }^{52}$ Management of ganciclovir-resistant CMV includes a combination of cautious reduction in immunosuppression, CMV-immunoglobulin, and an alternative antiviral strategy such as foscarnet, cidofovir and sometimes high-dose ganciclovir depending on resistance phenotype. ${ }^{53-55}$ Novel agents such as maribavir appear to have efficacy for the treatment of resistant CMV. Letermovir as treatment is poorly studied to date, but appears to have a low barrier to resistance and may have more utility as secondary prophylaxis once the CMV viral load is suppressed and undetectable adoptive $\mathrm{T}$ cell immunotherapy is an investigational modality which holds promise. ${ }^{56}$ Data are limited in this area and there are no specific studies on the management of resistant CMV in post-transplant CF patients. Further studies are required.

\section{Epstein-Barr Virus}

Epstein-Barr virus (EBV) is a $\gamma$-herpesvirus which is even more prevalent than $\mathrm{CMV}$, with approximately $85 \%$ of individuals seropositive by 25 years of age. ${ }^{57}$ Latent infection persists in B cells. In solid organ and hematologic transplantation, there is strong evidence that immunosuppression permits EBV to exert an oncogenic effect on $\mathrm{B}$ cells to precipitate post-transplant lymphoproliferative disorder (PTLD). ${ }^{58}$ PTLD is the most common non-skin malignancy after SOT and serological mismatch enormously increases this risk. ${ }^{59}$ EBV-mismatched CF patients have an even higher risk of PTLD, with a registry study of over 30,000 lung transplant recipients demonstrating 31\% will be affected. ${ }^{60,61}$ Although there is a lack of strong data supporting this strategy, many centers attempt to prevent PTLD in serologically mismatched patients via lifelong antiviral prophylaxis. ${ }^{62}$ Management of PTLD usually involves a stepwise combination of reduction in immunosuppression, rituximab, and chemotherapy/radiotherapy depending on extent and phenotype of disease. ${ }^{63-66}$

\section{Polyomaviruses}

Polyomaviruses are nonenveloped double-stranded DNA viruses. The commonest is $\mathrm{BK}$ virus (BKV) which persists as a latent infection in renal tubular and uroepithelial cells in approximately $80 \%$ of adults and reactivates in $25-30 \%$ of renal transplant recipients, with $1-10 \%$ developing BKV-associated nephropathy. ${ }^{67}$ BKV-associated nephropathy and presumed BKV-driven urological malignancies have been reported after LTx, including in CF patients. ${ }^{68,69}$ The only proven therapy is reduction in immunosuppression (often withholding the cell-cycle inhibitor and temporarily or permanently exchanging the calcineurin inhibitor for a mammalian target of rapamycin inhibitor), but intravenous immunoglobulin, leflunomide and cidofovir have also been employed. ${ }^{70,71}$

John Cunningham virus (JCV) is a neutrotropic polyomavirus that can cause progressive multifocal leukoencephalopathy in immunocompromised hosts. ${ }^{72}$ Although it remains very rare after LTx, with only several cases reported and none in CF patients, this demyelinating disease of the central nervous system frequently causes severe morbidity or death and thus, a high index of clinical suspicion should be maintained. ${ }^{73,74}$

\section{Fungal Infections}

Fungal pathogens following CF-LTx are of particular importance, given fungi are commonly found in the native $\mathrm{CF}$ airway. ${ }^{75}$ Due to the higher strength of initial immune suppression, the first year following LTx represents significant vulnerability to invasive fungal disease, contributing to significant morbidity and mortality. Invasive disease with Aspergillus fumigatus has a significant mortality (41$51 \%),{ }^{76}$ followed by Candida albicans and Cryptococcus spp. (23\%). ${ }^{77}$ In addition, reported mortality from invasive 
Scedosporium/Lomentospora spp. disease is close to $100 \%{ }^{78}$ Respiratory manifestations of fungal disease post-LTx include fungal pneumonia, other manifestations of invasive disease or local infection of the anastomosis (ie, tracheobronchitis or bronchial anastomotic infection) or colonization. ${ }^{75}$

\section{Aspergillus spP}

Invasive Aspergillus spp. disease are typically treated with triazoles such as posaconazole or voriconazole, needing close therapeutic drug monitoring and consideration of interactions with calcineurin inhibitors given its moderate inhibition of the CYP3A4 enzyme. ${ }^{75}$ Isavuconazole is the newest extended spectrum triazole antifungal, approved as an alternative to voriconazole for treatment against invasive aspergillosis and as an alternative treatment to liposomal amphotericin B for mucormycosis. Unlike most other azoleantifungals, isavuconazole has excellent oral bioavailability and predictable linear pharmacokinetics in adults, with reduced impact from genetic polymorphisms, and reduced inter-patient variability. Isavuconazole is a mild inhibitor of CYP3A4, and causes increased serum concentration of calcineurin inhibitors, but much less than with posaconazole and voriconazole; but, dose adjustments are still required. In addition, isavuconazole increases serum concentration of mycophenolate, and monitoring for mycophenolate toxicity is required. ${ }^{79}$

\section{Candida spp}

Retrospective analysis of over 25,000 respiratory samples from a national German registry reports up to $75 \%$ of patients with CF isolated yeast (mainly Candida spp.) and around 35\% isolated Aspergillus spp. ${ }^{80}$ Candida albicans is the most common Candida spp. isolated from the CF airway, followed by C. dubliniensis, C. glabrata complex and $C$. parapsilosis complex. Although the Candida spp. do not commonly cause pulmonary exacerbations in CF patients, a recent retrospective analysis over 16-years revealed that colonization (in particular C. albicans and $C$. dubliniensis) was associated with a decline in lung function. ${ }^{81}$ In addition, colonized patients who require central venous access are at risk of Candida spp. funge$\mathrm{mia} / \mathrm{sepsis}$ and endocarditis. In a survey of bloodstream infections post LTx, Candida spp. were the second most common. ${ }^{82}$ Randomized trials support the treatment for invasive candidemia typically with echinocandin therapy (anidulafungin or caspofungin) over fluconazole amphotericin B. ${ }^{83,84}$ Non-neutropenic patients who are not critically unwell and unlikely to have fluconazole resistant organisms (eg, C. glabrata or C. krusei) can be treated with fluconazole, particularly as step-down therapy.

\section{Scedosporium spp. and Lomentospora spp}

Filamentous fungi (S. apiospermum/L. prolificans-formerly known as $S$. prolificans) are reported in up to $4 \%$ of CF patients, and multiple single-center studies demonstrate similar rates in CF-LTx patients. ${ }^{80,85} \mathrm{~S}$. apiospermum/L. prolificans are intrinsically multiresistant pathogens that often require complex surgical debridement and prolonged multidrug regimens with significant morbidity/mortality. ${ }^{85,86}$ Treatments for these fungi are based on expert opinion and retrospective data. S. apiospermum is treated either with voriconazole monotherapy, or in conjunction with terbinafine. ${ }^{87,88}$ Based on a review of the literature from 2000-2018 and Fungiscope (an international rare invasive fungal registry), patients with voriconazole-based therapy had longer overall survival and reduced 42-day mortality compared to amphotericin-based regimens. ${ }^{89}$ Infections with $L$. prolificans are aggressive and often fatal, and treatments must be tailored on a caseby-case basis. Surgical debridement and reduction in immune suppression are often considered. Although $L$. prolificans has greater intrinsic resistance to voriconazole, multidrug regimens involving either posaconazole/voriconazole and terbinafine have been reported with reduced mortality, ${ }^{90}$ although limited data is available.

\section{Fungal Prophylaxis}

There is significant global discordance in the fungal prophylaxis strategy that should be used post-LTx, and available data are contradictory. ${ }^{91}$ A review and meta-analysis of 748 LTx recipients suggested that universal prophylaxis (agents included were fluconazole, voriconazole, and inhaled amphotericin B) reduced pulmonary invasive aspergillosis; however, limitations such as single center data and nonrandomized protocols were acknowledged. ${ }^{92}$ Subsequently, two recent meta-analyses reveal no difference in the odds of fungal infection with universal prophylaxis compared to no prophylaxis following LTx. ${ }^{93,94}$ Long-term exposure to antifungal medication has been reported as the major risk factor in the emergence of multiresistant fungal infections post-LTx ${ }^{85}$ and the question remains as to whether universal prophylaxis risks breeding increased resistance to first-line antifungal medication without a mortality benefit.

In place of universal fungal prophylaxis, pre-emptive strategies have been successfully applied by large LTx 
units. This involves treatment with antimould agents after initial isolation on surveillance bronchoscopy/sputum culture or following positive galactomannan on bronchoalveolar lavage sample. This strategy has been reported to reduce antifungal exposure by $60 \%$ compared to universal prophylaxis, without affecting mortality at one year. ${ }^{95}$ Head-to-head randomized trials are needed to confirm which approach is superior.

\section{Novel Antifungals}

Olorofim (formerly F901318) is a novel investigational antifungal agent. This mould-active antifungal targets dihydroorotate dehydrogenase and inhibits pyrimidine biosynthesis. It is the first member of the orotomide class and is currently being evaluated for use against resistant moulds, including species with intrinsic or acquired resistance to azoles and amphotericin B; however, it lacks activity against yeasts and the Mucorales. ${ }^{96}$ Published experience is currently limited to case reports (abstracts) against resistant moulds causing persistent infections and is quite promising. ${ }^{97-99}$ A Phase II clinical trial for patients with invasive fungal disease (Scedosporium spp., Lomentospora spp. and azole-resistant Aspergillus spp.) is currently recruiting (NCT03583164).

Azole-resistant Aspergillus spp. infections are increasingly prevalent in $\mathrm{CF}$ patients, and can reach high prevalence in CF patients who are chronically treated with azoles. A second mould-active antifungal agent, fosmanogepix (formerly APX001A), which blocks glycophosphatidylinositol biosynthesis is currently under development. ${ }^{100}$

\section{Conclusions}

CF the is one of the most common indications for LTx and a diverse airway microbiome with high exposure to antimicrobial agents are hallmarks of this disease state. Improving multidisciplinary care and evolving CFTRdirected therapies are successfully preserving native lung function and delaying LTx. However, this delay may come with further challenges such as increasing multidrug resistance. Although few infections are established contraindications to LTx, immune suppression and pathogen reservoirs encourage re-emergent infections and threaten early and late LTx outcomes. Antimicrobial prophylaxis strategies are varied across virus, bacterial, and fungal pathogens, with a wide variation in global practice. Short-term bacterial prophylaxis against donor-derived infections and extended viral prophylaxis are generally well accepted strategies (depending on individual risk profiles); however, the approach to antifungal prophylaxis is less clear. Resistance to antimicrobial agents is emerging at a rapid rate, and the armamentarium against these pathogens is only slowly growing. Cautious and directed use of antimicrobial agents against multiresistant pathogens as guided by local epidemiology and resistance profiles and for well-defined timeframes are likely to continue to support the increased survival and improved quality of life experienced by CF patients following LTx.

\section{Funding}

No funding was sought for this review.

\section{Disclosure}

The authors report no conflicts of interest in this work.

\section{References}

1. Cutting GR. MODIFIER GENETICS: cystic Fibrosis. Annu Rev Genom Hum Genet. 2005;6(1):237-260. doi:10.1146/annurev. genom.6.080604.162254

2. Ratjen F, Bell SC, Rowe SM, Goss CH, Quittner AL, Bush A. Cystic fibrosis. Nat Rev Dis Primers. 2015;1(1):15010. doi:10. $1038 /$ nrdp. 2015.10

3. Keogh RH, Szczesniak R, Taylor-Robinson D, Bilton D. Up-todate and projected estimates of survival for people with cystic fibrosis using baseline characteristics: a longitudinal study using UK registry data. J Cyst Fibros. 2018;17(2):218-227. doi:10.10 16/j.jcf2017.11.019

4. Nettie Burke SA. The Australian cystic fibrosis data registry annual report, 2019. Monash University, Department of Epidemiology and Preventive Medicine; 2021. Available from: https://www.cysticfibrosis.org.au/getmedia/bcab56d9-5bbe-4b199486-85a0ad2c2a21/ACFDR-2019-Annual-Report.pdf.aspx. Accessed June 15, 2021.

5. Thabut G, Christie JD, Mal H, et al. Survival benefit of lung transplant for cystic fibrosis since lung allocation score implementation. Am J Respir Crit Care Med. 2013;187(12):1335-1340. doi:10.1164/rccm.201303-04290C

6. Chambers DC, Yusen RD, Cherikh WS, et al. The Registry of the International Society for heart and lung transplantation: thirtyfourth adult lung and heart-lung transplantation report-2017; focus theme: allograft ischemic time. J Heart Lung Transpl. 2017;36(10):1047-1059. doi:10.1016/j.healun.2017.07.016

7. Benden C, Goldfarb SB, Stehlik J. An aging population of patients with cystic fibrosis undergoes lung transplantation: an analysis of the ISHLT Thoracic Transplant Registry. J Heart Lung Transpl. 2019;38(11):1162-1169. doi:10.1016/j.healun.2019.06. 025

8. Paraskeva MA, Edwards LB, Levvey B, et al. Outcomes of adolescent recipients after lung transplantation: an analysis of the International Society for Heart and Lung Transplantation Registry. J Heart Lung Transpl. 2018;37(3):323-331. doi:10.10 16/j.healun.2017.02.017

9. Thomas O'Neil BM. Cystic fibrosis foundation patient registry 2019 annual data report. Bethesda, Maryland: (C2020 Cystic Fibrosis Foundation; 2020. Available from: https://www.cff.org/ Research/Researcher-Resources/Patient-Registry/2019-PatientRegistry-Annual-Data-Report.pdf. Accessed June 15, 2021.

10. Huang YJ, LiPuma JJ. The microbiome in cystic fibrosis. Clin Chest Med. 2016;37(1):59-67. doi:10.1016/j.ccm.2015.10.003 
11. Aaron SD. Changes in the cystic fibrosis airway microbiome after lung transplant: the more things change, the more they stay the same. Annals ATS. 2016;13(12):2109-2110. doi:10.1513/ AnnalsATS.201609-700ED

12. Breijyeh Z, Jubeh B, Karaman R. Resistance of gram-negative bacteria to current antibacterial agents and approaches to resolve it. Molecules. 2020;25(6):1340. doi:10.3390/molecules 25061340

13. Rocha GA, Lima DF, Rodrigues ER, et al. Species distribution, sequence types and antimicrobial resistance of Acinetobacter spp. from cystic fibrosis patients. Epidemiol Infect. 2018;146(4):524530. doi:10.1017/S0950268817002849

14. Vermeulen F, Proesmans M, Vermaelen M, Boon M, De Boeck K. Isolation of Enterobacteriaceae in airway samples is associated with worse outcome in preschool children with cystic fibrosis. $J$ Cystic Fibrosis. 2020;19(3):365-369. doi:10.1016/j.jcf.2019.10. 019

15. Egan T. Long term results of lung transplantation for cystic fibrosis. Eur J Cardio Thorac Surg. 2002;22(4):602-609. doi:10.1016/S1010-7940(02)00376-7

16. Dobbin C, Maley M, Harkness J, et al. The impact of panresistant bacterial pathogens on survival after lung transplantation in cystic fibrosis: results from a single large referral centre. $J$ Hosp Infect. 2004;56(4):277-282. doi:10.1016/j.jhin.2004.01.003

17. Bonvillain RW, Valentine VG, Lombard G, LaPlace S, Dhillon G, Wang G. Post-operative infections in cystic fibrosis and noncystic fibrosis patients after lung transplantation. J Heart Lung Transpl. 2007;26(9):890-897. doi:10.1016/j.healun.2007.07.002

18. Boyd SE, Livermore DM, Hooper DC, Hope WW. Metallo- $\beta$ lactamases: structure, function, epidemiology, treatment options, and the development pipeline. Antimicrob Agents Chemother. 2020;64:10. doi:10.1128/AAC.00397-20

19. Pollini S, Mugnaioli C, Dolce D, et al. Chronic infection sustained by a Pseudomonas aeruginosa high-risk clone producing the VIM-1 metallo- $\beta$-lactamase in a cystic fibrosis patient after lung transplantation. J Cystic Fibrosis. 2018;17(4):470-474. doi:10.1016/j.jcf.2018.01.007

20. Carugati M, Piazza A, Peri AM, et al.; IFALT working group. Fatal respiratory infection due to ST308 VIM-1-producing Pseudomonas aeruginosa in a lung transplant recipient: case report and review of the literature. BMC Infect Dis. 2020;20 (1):635. doi:10.1186/s12879-020-05338-3

21. Pouch SM, Patel G; the AST Infectious Diseases Community of Practice. Multidrug-resistant gram-negative bacterial infections in solid organ transplant recipients-guidelines from the American Society of Transplantation Infectious Diseases Community of Practice. Clin Transplant. 2019;33(9). doi:10.1111/ctr.13594

22. Zhanel GG, Chung P, Adam H, et al. Ceftolozane/tazobactam: a novel cephalosporin/ $\beta$-lactamase inhibitor combination with activity against multidrug-resistant gram-negative bacilli. Drugs. 2014;74(1):31-51. doi:10.1007/s40265-013-0168-2

23. Arena F, Marchetti L, Henrici De Angelis L, et al. Ceftolozanetazobactam pharmacokinetics during extracorporeal membrane oxygenation in a lung transplant recipient. Antimicrob Agents Chemother. 2019;63(3). doi:10.1128/AAC.02131-18

24. Puzniak L, Dillon R, Palmer T, Collings H, Enstone A. Realworld use of ceftolozane/tazobactam: a systematic literature review. Antimicrob Resist Infect Control. 2021;10(1):68. doi:10. 1186/s13756-021-00933-8

25. Pogue JM, Bonomo RA, Kaye KS. Ceftazidime/avibactam, meropenem/vaborbactam, or both? Clinical and formulary considerations. Clin Infect Dis. 2019;68(3):519-524. doi:10.1093/cid/ ciy576

26. Pouch SM. New drugs for difficult bugs: management of multidrug-resistant gram-negative infections in solid organ transplant recipients. Curr Opin Organ Transplant. 2021. doi:10.1097/ MOT.0000000000000890
27. Koutsokera A, Varughese RA, Sykes J, et al. Pre-transplant factors associated with mortality after lung transplantation in cystic fibrosis: a systematic review and meta-analysis. J Cystic Fibrosis. 2019;18(3):407-415. doi:10.1016/j.jcf.2018.10.013

28. Courtney JM, Dunbar KEA, McDowell A, et al. Clinical outcome of Burkholderia cepacia complex infection in cystic fibrosis adults. $J$ Cystic Fibrosis. 2004;3(2):93-98. doi:10.1016/j.jcf.2004.01.005

29. Snell G, Smibert O, Tullis E. Burkholderia in transplant: important to speciate and important to treat. In: Morris MI, Kotton CN, Wolfe C, editors. Emerging Transplant Infections. Springer International Publishing; 2020:1-19. doi:10.1007/978-3-03001751-4 22-1

30. Bartley BL, Gardner KJ, Spina S, et al. High-dose inhaled nitric oxide as adjunct therapy in cystic fibrosis targeting Burkholderia multivorans. Case Rep Pediatr. 2020;2020:1-6. doi:10.1155/2020/1536714

31. McCallin S, Brüssow H. Clinical trials of bacteriophage therapeutics. In: Harper DR, Abedon ST, Burrowes BH, McConville ML, editors. Bacteriophages. Springer International Publishing; 2021:1099-1127. doi:10.1007/978-3-319-41986-2_38

32. Kamal F, Dennis JJ, Elliot MA. Burkholderia cepacia Complex Phage-Antibiotic Synergy (PAS): antibiotics stimulate lytic phage activity. Elliot MA, ed. Appl Environ Microbiol. 2015;81 (3):1132-1138. doi:10.1128/AEM.02850-14

33. Zeriouh M, Sabashnikov A, Patil NP, et al. Use of taurolidine in lung transplantation for cystic fibrosis and impact on bacterial colonization†. Eur J Cardio Thorac Surg. 2018;53(3):603-609. doi:10.1093/ejcts/ezx359

34. Adjemian J, Olivier KN, Prevots DR. Erratum: epidemiology of pulmonary nontuberculous mycobacterial sputum positivity in patients with cystic fibrosis in the United States, 2010-2014. Annals ATS. 2018;15(9):1114-1115. doi:10.1513/AnnalsATS. 159erratum

35. Piersimoni C. Nontuberculous mycobacteria infection in solid organ transplant recipients. Eur J Clin Microbiol Infect Dis. 2012;31(4):397-403. doi:10.1007/s10096-011-1329-4

36. Degiacomi S, Chiarelli R, Makarov P. Mycobacterium abscessus, an emerging and worrisome pathogen among cystic fibrosis patients. IJMS. 2019;20(23):5868. doi:10.3390/ijms20235868

37. Vazirani J, Snell GI, Westall GP. Prolonged survival after lung transplantation in the absence of conventional immunosuppression. J Heart Lung Transpl. 2020;39(10):1159-1162. doi:10. 1016/j.healun.2020.06.018

38. Daley CL, Iaccarino JM, Lange C, et al. Treatment of nontuberculous mycobacterial pulmonary disease: an official ATS/ERS/ ESCMID/IDSA clinical practice guideline. Clin Infect Dis. 2020;71(4):e1-e36. doi:10.1093/cid/ciaa241

39. Weng Y-W, Huang C-K, Sy C-L, Wu K-S, Tsai H-C, Lee SS-J. Treatment for Mycobacterium abscessus complex-lung disease. $J$ Formosan Med Assoc. 2020;119:S58-S66. doi:10.1016/j.jfma. 2020.05.028

40. Higuchi T, Oto T, Millar IL, Levvey BJ, Williams TJ, Snell GI. Preliminary report of the safety and efficacy of hyperbaric oxygen therapy for specific complications of lung transplantation. J Heart Lung Transpl. 2006;25(11):1302-1309. doi:10.1016/j.healun.20 06.08 .006

41. Tan S, Kasperbauer S. Nontuberculous mycobacteria. Semin Respir Crit Care Med. 2021;42(04):567-586. doi:10.1055/s0041-1730997

42. Shirley M. Correction to: amikacin liposome inhalation suspension: a review in mycobacterium avium complex lung disease. Drugs. 2019;79(7):791. doi:10.1007/s40265-019-01111-2

43. Griffith DE, Eagle G, Thomson R, et al. Amikacin liposome inhalation suspension for treatment-refractory lung disease caused by Mycobacterium avium Complex (CONVERT). A prospective, open-label, randomized study. Am J Respir Crit Care Med. 2018;198(12):1559-1569. doi:10.1164/rccm.201807-13180C 
44. Winthrop KL, Ku JH, Marras TK, et al. The tolerability of linezolid in the treatment of nontuberculous mycobacterial disease. Eur Respir J. 2015;45(4):1177-1179. doi:10.1183/09031936.00169114

45. Poon YK, La Hoz RM, Hynan LS, Sanders J, Monogue ML. Tedizolid vs linezolid for the treatment of nontuberculous mycobacteria infections in solid organ transplant recipients. Open Forum Infect Dis. 2021;8(4):ofab093. doi:10.1093/ofid/ofab093

46. Söderberg-Nauclér C, Fish KN, Nelson JA. Reactivation of latent human cytomegalovirus by allogeneic stimulation of blood cells from healthy donors. Cell. 1997;91(1):119-126. doi:10.1016/ S0092-8674(01)80014-3

47. Paraskeva M, Bailey M, Levvey BJ, et al. Cytomegalovirus replication within the lung allograft is associated with bronchiolitis obliterans syndrome: CMV in the allograft is associated with BOS. Am J Transpl. 2011;11(10):2190-2196. doi:10.1111/j.16006143.2011.03663.x

48. Duncan AJ, Dummer JS, Paradis IL, et al. Cytomegalovirus infection and survival in lung transplant recipients. $J$ Heart Lung Transplant. 1991;10(5 Pt 1):638-644; discussion 645-646.

49. van Delden C, Stampf S, Hirsch HH, et al. Burden and timeline of infectious diseases in the first year after solid organ transplantation in the Swiss transplant cohort study. Clin Infect Dis. 2020;71 (7):e159-e169. doi:10.1093/cid/ciz1113

50. Heliövaara E, Husain S, Martinu T, et al. Drug-resistant cytomegalovirus infection after lung transplantation: incidence, characteristics, and clinical outcomes. J Heart Lung Transplant. 2019;38 (12):1268-1274. doi:10.1016/j.healun.2019.09.005

51. Gagermeier JP, Rusinak JD, Lurain NS, et al. Subtherapeutic ganciclovir (GCV) levels and GCV-resistant cytomegalovirus in lung transplant recipients. Transpl Infect Dis. 2014;16(6):941950. doi:10.1111/tid.12317

52. Kotton CN, Kumar D, Caliendo AM, et al. The third international consensus guidelines on the management of cytomegalovirus in solid-organ transplantation. Transplantation. 2018;102(6):900931. doi:10.1097/TP.0000000000002191

53. Wilkens H, Sester M. Treatment of cytomegalovirus infection with cidofovir and CMV immune globulin in a lung transplant recipient. Case Rep Transplant. 2016;2016:4560745. doi:10.1155/ 2016/4560745

54. Schulz U, Solidoro P, Müller V, et al. CMV immunoglobulins for the treatment of CMV infections in thoracic transplant recipients. Transplantation. 2016;100(Suppl 3):S5-10. doi:10.1097/TP.000 0000000001097

55. Veit T, Munker D, Kauke T, et al. Letermovir for difficult to treat cytomegalovirus infection in lung transplant recipients. Transplantation. 2020;104(2):410-414. doi:10.1097/TP.0000000 000002886

56. Smith C, Beagley L, Rehan S, et al. Autologous adoptive T-cell therapy for recurrent or drug-resistant cytomegalovirus complications in solid organ transplant recipients: a single-arm open-label phase I clinical trial. Clin Infect Dis. 2019;68(4):632-640. doi:10.1093/cid/ciy549

57. Kuri A, Jacobs BM, Vickaryous N, et al. Epidemiology of Epstein-Barr virus infection and infectious mononucleosis in the United Kingdom. BMC Public Health. 2020;20(1):912. doi:10. 1186/s12889-020-09049-x

58. Liebowitz D. Epstein-Barr virus and a cellular signaling pathway in lymphomas from immunosuppressed patients. $N$ Engl $J$ Med. 1998;338(20):1413-1421. doi:10.1056/NEJM199805143382003

59. Adami J, Gäbel H, Lindelöf B, et al. Cancer risk following organ transplantation: a nationwide cohort study in Sweden. $\mathrm{Br} J$ Cancer. 2003;89(7):1221-1227. doi:10.1038/sj.bjc.6601219

60. Saueressig MG, Boussaud V, Amrein C, Guillemain R, Souilamas J, Souilamas R. Risk factors for post-transplant lymphoproliferative disease in patients with cystic fibrosis. Clin Transplant. 2011;25(4):E430-436. doi:10.1111/j.1399-0012.2011.01464.x
61. Lowery EM, Adams W, Grim SA, Clark NM, Edwards L, Layden JE. Increased risk of PTLD in lung transplant recipients with cystic fibrosis. J Cyst Fibros. 2017;16(6):727-734. doi:10.1016/ j.jcf.2017.03.013

62. AlDabbagh MA, Gitman MR, Kumar D, Humar A, Rotstein C, Husain S. The role of antiviral prophylaxis for the prevention of Epstein-Barr virus-associated posttransplant lymphoproliferative disease in solid organ transplant recipients: a systematic review. Am J Transplant. 2017;17(3):770-781. doi:10.1111/ajt.14020

63. Reshef R, Vardhanabhuti S, Luskin MR, et al. Reduction of immunosuppression as initial therapy for posttransplantation lymphoproliferative disorder( $\star$ ). Am J Transplant. 2011;11(2):336347. doi:10.1111/j.1600-6143.2010.03387.x

64. Parker A, Bowles K, Bradley JA, et al. Management of posttransplant lymphoproliferative disorder in adult solid organ transplant recipients - BCSH and BTS Guidelines. Br J Haematol. 2010;149(5):693-705. doi:10.1111/j.1365-2141.2010.08160.x

65. Choquet S, Oertel S, LeBlond V, et al. Rituximab in the management of post-transplantation lymphoproliferative disorder after solid organ transplantation: proceed with caution. Ann Hematol. 2007;86(8):599-607. doi:10.1007/s00277-007-0298-2

66. Trappe RU, Dierickx D, Zimmermann H, et al. Response to rituximab induction is a predictive marker in B-cell post-transplant lymphoproliferative disorder and allows successful stratification into rituximab or R-CHOP consolidation in an international, prospective, multicenter phase II trial. J Clin Oncol. 2017;35(5):536-543. doi:10.1200/JCO.2016.69.3564

67. Viswesh V, Yost SE, Kaplan B. The prevalence and implications of BK virus replication in non-renal solid organ transplant recipients: a systematic review. Transplant Rev (Orlando). 2015;29 (3):175-180. doi:10.1016/j.trre.2015.02.004

68. Dufek S, Haitel A, Müller-Sacherer T, Aufricht C. Duct Bellini carcinoma in association with BK virus nephropathy after lung transplantation. J Heart Lung Transplant. 2013;32(3):378-379. doi:10.1016/j.healun.2012.11.033

69. Kuppachi S, Holanda D, Eberlein M, et al. An unexpected surge in plasma BKPyV viral load heralds the development of BKPyVassociated metastatic bladder cancer in a lung transplant recipient with BKPyV nephropathy. Am J Transplant. 2017;17(3):813-818. doi:10.1111/ajt.14057

70. Moscarelli L, Caroti L, Antognoli G, et al. Everolimus leads to a lower risk of BKV viremia than mycophenolic acid in de novo renal transplantation patients: a single-center experience. Clin Transplant. 2013;27(4):546-554. doi:10.1111/ctr.12151

71. Wojciechowski D, Chandran S, Webber A, Hirose R, Vincenti F. Mycophenolate mofetil withdrawal with conversion to everolimus to treat BK virus infection in kidney transplant recipients. Transplant Proc. 2017;49(8):1773-1778. doi:10.1016/j. transproceed.2017.06.030

72. Shitrit D, Lev N, Bar-Gil-Shitrit A, Kramer MR. Progressive multifocal leukoencephalopathy in transplant recipients. Transpl Int. 2005;17(11):658-665. doi:10.1007/s00147-004-0779-3

73. Ishii K, Yamamoto F, Homma S, et al. Probable progressive multifocal leukoencephalopathy-immune reconstitution inflammatory syndrome with immunosuppressant dose reduction following lung transplantation: a case report and literature review. BMC Neurol. 2019;19(1):263. doi:10.1186/ s12883-019-1493-1

74. Crowhurst T, Koszyca B, Holmes M, Holmes-Liew C-L. Progressive multifocal leukoencephalopathy in a lung transplant recipient presenting with memory impairment: case report and literature review. Transpl Infect Dis. 2020;22(3):e13293. doi:10.1111/tid.13293

75. Renner S, Nachbaur E, Jaksch P, Dehlink E. Update on respiratory fungal infections in cystic fibrosis lung disease and after lung transplantation. JoF. 2020;6(4):381. doi:10.3390/jof6040381 
76. Singh N, Husain S. Aspergillus infections after lung transplantation: clinical differences in type of transplant and implications for management. J Heart Lung Transpl. 2003;22(3):258-266. doi:10. 1016/S1053-2498(02)00477-1

77. Pappas PG, Alexander BD, Andes DR, et al. Invasive fungal infections among organ transplant recipients: results of the Transplant-Associated Infection Surveillance Network (TRANSNET). Clin Infect Dis. 2010;50(8):1101-1111. doi:10. 1086/651262

78. Solé A, Salavert M. Fungal infections after lung transplantation. Transplant Rev. 2008;22(2):89-104. doi:10.1016/j.trre.2007.12. 007

79. Li J, Nguyen C, Garcia-Diaz J. Role of new antifungal agents in the treatment of invasive fungal infections in transplant recipients: isavuconazole and new posaconazole formulations. JoF. 2015;1(3):345-366. doi:10.3390/jof1030345

80. Ziesing S, Suerbaum S, Sedlacek L. Fungal epidemiology and diversity in cystic fibrosis patients over a 5-year period in a national reference center. Med Myco. 2016;54(8):781-786. doi:10.1093/mmy/myw035

81. Al Shakirchi M, Klingspor L, Bergman P, Hjelte L, de Monestrol I. A 16-year retrospective study on fungal prevalence and diversity in patients with cystic fibrosis: candida dubliniensis was associated with a decline in lung function. Int $J$ Infect Dis. 2020;96:663-670. doi:10.1016/j.ijid.2020.05.063

82. Palmer SM, Alexander BD, Sanders LL, et al. Significance of blood stream infection after lung transplantation: analysis in 176 consecutive patients1. Transplantation. 2000;69(11):2360-2366. doi:10.1097/00007890-200006150-00025

83. Mora-Duarte J, Betts R, Rotstein C, et al. Comparison of caspofungin and amphotericin B for invasive candidiasis. $N$ Engl J Med. 2002;347(25):2020-2029. doi:10.1056/NEJMoa021585

84. Reboli AC, Rotstein C, Pappas PG, et al. Anidulafungin versus fluconazole for invasive candidiasis. $N$ Engl J Med. 2007;356 (24):2472-2482. doi:10.1056/NEJMoa066906

85. Vazirani J, Westall GP, Snell GI, Morrissey CO. Scedosporium apiospermum and Lomentospora prolificans in lung transplant patients - a single center experience over 24 years. Transpl Infect Dis. 2021;23(3). doi:10.1111/tid.13546

86. Denton EJ, Smibert O, Gooi J, et al. Invasive Scedosporium sternal osteomyelitis following lung transplant: cured. Med Mycol Case Rep. 2016;12:14-16. doi:10.1016/j.mmcr.2016. 07.001

87. Husain S, Muñoz P, Forrest $G$, et al. Infections due to Scedosporium apiospermum and Scedosporium prolificans in transplant recipients: clinical characteristics and impact of antifungal agent therapy on outcome. Clin Infect Dis. 2005;40(1):8999. doi: $10.1086 / 426445$

88. Troke P, Aguirrebengoa K, Arteaga C, et al. Treatment of scedosporiosis with voriconazole: clinical experience with 107 patients. Antimicrob Agents Chemother. 2008;52(5):1743-1750. doi:10. 1128/AAC.01388-07
89. Seidel D, Meißner A, Lackner M, et al. Prognostic factors in 264 adults with invasive Scedosporium spp. and Lomentospora prolificans infection reported in the literature and FungiScope ${ }^{\circledR}$. Crit Rev Microbiol. 2019;45(1):1-21. doi:10.1080/1040841X.2018.1514366

90. Jenks JD, Seidel D, Cornely OA, et al. Clinical characteristics and outcomes of invasive Lomentospora prolificans infections: analysis of patients in the FungiScope ${ }^{\circledR}$ registry. Mycoses. 2020;63 (5):437-442. doi:10.1111/myc. 13067

91. Neoh CF, Snell GI, Kotsimbos T, et al. Antifungal prophylaxis in lung transplantation-a world-wide survey: world-wide survey of antifungal prophylaxis. Am J Transpl. 2011;11(2):361-366. doi:10.1111/j.1600-6143.2010.03375.x

92. Pilarczyk K, Haake N, Heckmann J, et al. Is universal antifungal prophylaxis mandatory in adults after lung transplantation? A review and meta-analysis of observational studies. Clin Transplant. 2016;30(12):1522-1531. doi:10.1111/ctr.12854

93. Pennington KM, Baqir M, Erwin PJ, Razonable RR, Murad MH, Kennedy CC. Antifungal prophylaxis in lung transplant recipients: a systematic review and meta-analysis. Transpl Infect Dis. 2020;22(4). doi:10.1111/tid.13333

94. Bhaskaran A, Mumtaz K, Husain S. Anti-aspergillus prophylaxis in lung transplantation: a systematic review and meta-analysis. Curr Infect Dis Rep. 2013;15(6):514-525. doi:10.1007/s11908013-0380-y

95. Husain S, Bhaskaran A, Rotstein C, et al. A strategy for prevention of fungal infections in lung transplantation: role of bronchoalveolar lavage fluid galactomannan and fungal culture. J Heart Lung Transpl. 2018;37(7):886-894. doi:10.1016/j.healun.2018.02.006

96. Wiederhold NP. Review of the novel investigational antifungal olorofim. JoF. 2020;6(3):122. doi:10.3390/jof6030122

97. Tio SH, Thursky K, Ng G, Rex JH, Carney D, Slavin M. Olorofim for a case of severe disseminated Lomentospora prolificans infections. In Proceedings of the 30th European Congress of Clinical Microbiology and Infectious Diseases, Paris, France. April 182020

98. Chen S, Rai NJ, Cunneen S, et al. A case of Lomentospora prolificans treated with the novel antifungal olorofim. In Proceedings of the 30th European Congress of Clinical Microbiology and Infectious Diseases, Paris, France. 2020: abstr. 2585.

99. Morrissey CO, Garlick J, Gaffney N, Harvey E, Rex J. Long-term use of olorofim in the treatment of scedosporium apiospermum chest wall infection. In Proceedings of the 31st European Congress of Clinical Microbiology and Infectious Diseases, Vienna, Austria. 2021:abstr.2641.

100. Zhao M, Lepak AJ, Marchillo K, et al. APX001 pharmacokinetic/ pharmacodynamic target determination against aspergillus fumigatus in an in vivo model of invasive pulmonary aspergillosis. Antimicrob Agents Chemother. 2019;63:e02372-18. doi:10.1128/ AAC.02372-18
Infection and Drug Resistance

\section{Publish your work in this journal}

Infection and Drug Resistance is an international, peer-reviewed openaccess journal that focuses on the optimal treatment of infection (bacterial, fungal and viral) and the development and institution of preventive strategies to minimize the development and spread of resistance. The journal is specifically concerned with the epidemiology of antibiotic resistance and the mechanisms of resistance development and diffusion in both hospitals and the community. The manuscript management system is completely online and includes a very quick and fair peerreview system, which is all easy to use. Visit http://www.dovepress.com/ testimonials.php to read real quotes from published authors 